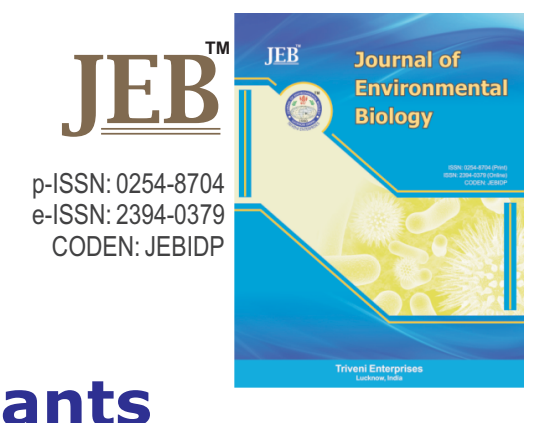

\title{
Antifeedant and ovipositional deterrent activity of medicinal plants of Western Himalaya on Plutella xylostella
}

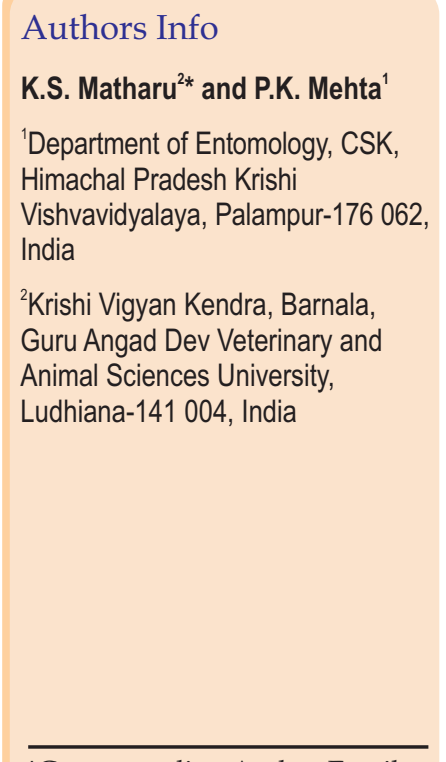

${ }^{*}$ Corresponding Author Email : matharu38@rediffmail.com

\section{Key words}

Acorus calamus

Antifeedant effect

Oviposition deterrents

Plutella xylostella

Vitex negundo

\section{Publication Info}

Paper received : 05.01.2017

Revised received: 01.10 .2017

Re-revised received : 30.01 .2018

Accepted: 09.02.2018

\begin{abstract}
Aim: Medicinal plants of Himalayan region is inadequately known for their role in pest management. The present study was conducted to assess the response of different extracts of Acorus calamus (L.) and Vitex negundo (L.) on antifeedant and ovipositional deterrent activity of Plutella xylostella.

Methodology: Acorus calamus (Rhizome) and Vitex negundo (leaves) were taken as an experimental material. Methanol (polar solvent) and hexane (non-polar solvent) were used for extraction. Antifeedant and ovipostional deterrent effect of two plants were workout against Plutella xylostella. The data were statistically analysed by t-tests for paired comparisons.
\end{abstract}

Results: Stronger ovipositional deterrent effects was observed in A. calamus (methanol extract) with higher oviposition deterrent indices (ODI) (38.7), followed by hexane extract of $V$. negundo. The leaves treated with plant extracts of $A$. calamus and $V$. negundo deterred the female of $P$. xylostella to some extent to lays eggs. After three days of treatment, methanol extract of $A$. calamus showed a residual deterrent effect to female of $P$. xylostella due to its low volatile nature.

Interpretation: Application of methanol and hexane extracts of $A$. calamus and $V$. negundo on host plants render them less attractive and show ovipositional deterrent to females of $P$. xylostella.

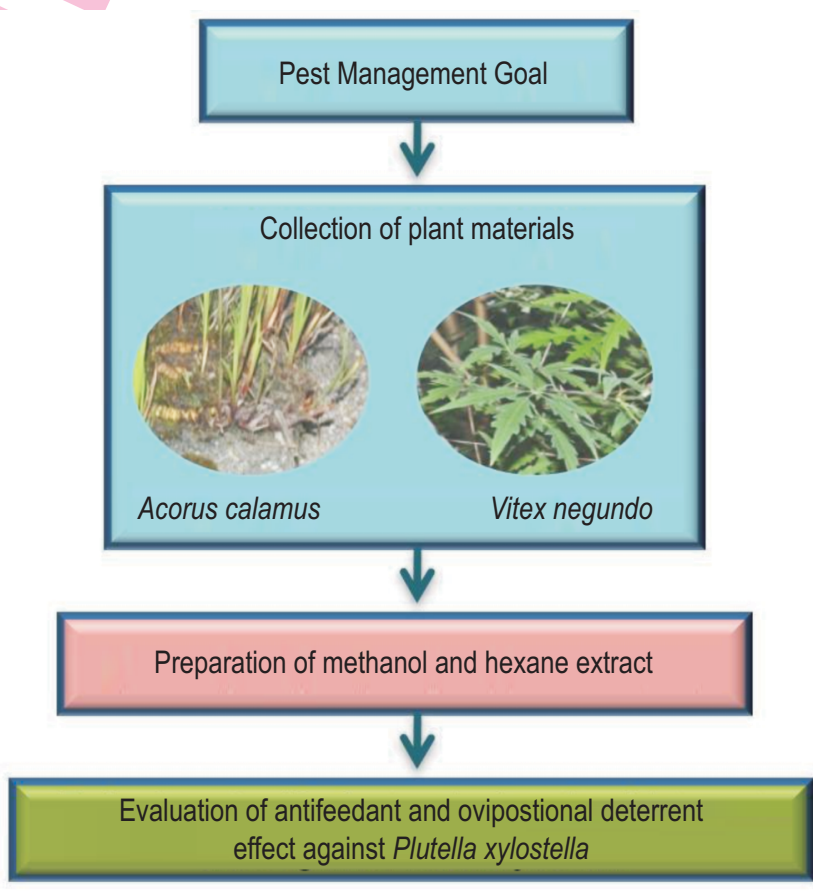




\section{Introduction}

Diamondback moth, Plutella xylostella (L.) (Lepidoptera: Plutellidae), is an important insect-pest that damages the cabbage plants (Sarfraz et al., 2006). It is adapted to wide range of agro-climatic conditions and cause serious economic losses to cabbage, cauliflower, broccoli, canola and brussels sprouts in 128 countries (Martínez-Castillo et al., 2002; Ahmad and Ansari, 2010). In last half century, this pest has developed resistance to chemical insecticide which have been used for their management, so safe and alternative to synthetic insecticide is needed (Talekar and Shelton, 1993). Plants are nature's chemica factories, providing the nature's richest source of chemicals (Singh, 2000). Plant families like Rutaceae, Annonaceae, Malvaceae, Labiateae, Canellaceae, Asteraceae and Meliaceae are a vast source of secondary plant substances (Jacobson, 1989), and approximately 2500 plants have been reported to possess insecticidal properties (Dhaliwal and Koul, 2011).

Plants like Acorus calamus and Vitex negundo manufacture different kinds of allelochemicals like gycosides, saponins, polyphenol which change the behavior of the insects and therefore, it is difficult for insects to develop resistance to these pesticides (Dhaliwal and Koul, 2011).

Antifeedant effect is essentially a pre-injective activity, based on chemosensory response, where insect rejects food treated with the compound and ingestion is reduced. This results in reduced growth and fecundity and prolonged developmental time. Antifeedant act as allomone substances which inhibit feeding and do not kill the insect-pests directly, but rather limit its developmental potential considerably and act as phagorepellent. The plant products applied in any form i.e., either as extracts or oils affects egg laying and egg hatching, influencing the reproduction potential of a pest is known as oviposition deterrents. Plant extract produces pungent smell which causes malfunctioning of the ovariole in female lepidopteran pest (Elumalai et al., 2005).

Mid hills of western Himalaya are endowed with a wide range of promising flora known for their medicinal values and history of usages to management of insect-pests (Tewary et al., 2005). For successful exploitation of natural compounds, screening of different plant extracts against polyphagous insects is required. The bioactivity of phytochemical extracts varies significantly with solvents used for the extraction and test insect (Ramya et al., 2008). Bioactive properties of $A$. calamus $L$. and V. negundo $L$. are well known. However, studies on the antifeedant and ovipostional deterrent activity of these plants are scanty and no quantitative reports are available on their activity against $P$. xylostella. Therefore, the present study was planned to evaluate the antifeedant and ovipositional deterrent activity of two medicinal plants against Diamondback moth, P. xylostella.

\section{Materials and Methods}

Plant extracts preparation: Plants viz., rhizome of $A$. calamus and leaves of $V$. negundo, were collected from the Kangra district (H.P). Different plant parts were cleaned three to four times with ordinary water and shade dried, then grounded in a grinder and these fine powder viz., brown (A. calamus) and greenish $(V$. negundo) were subjected to extraction. Dried powder forms were mixed with non-polar solvent (hexane) and polar solvent (methanol) for $48 \mathrm{hrs}$ and thereafter, passed through Whattman filter paper. Under reduced pressure and temperature $\left(38^{\circ} \mathrm{C}\right)$, extracts were evaporated to obtain crude extract by a using rotary evaporator. Desired concentrations were prepared by adding emulsifier (TritonX-100) to crude extract.

Experimental plants: For antifeedant and ovipositional deterrent experiments, cabbage plants, were grown in a tray $(58 x$ $32 \times 11.5 \mathrm{~cm})$ placed in green house conditions at $23 \pm 2^{\circ} \mathrm{C}$ temperature, $60 \pm 5 \% \mathrm{RH}$ and 14:10 (L: D) photoperiod. Each tray contained approximately 50 plants. These trays were put into rearing cages to avoid pre-egg laying and feeding on the seedling. After 20 days, seedling were separated and grown individually in single pots $(7 \times 10 \mathrm{~cm})$. For both experiments, forty five-day-old single potted cabbage plants were used.

Test insects: A culture of $P$. xylostella was established from a field collected population of Diamondback moth from cabbage grown in vegetable farm and maintained on cabbage in a growth chamber room at $25 \pm 2^{\circ} \mathrm{C}, 70 \pm 5 \% \mathrm{RH}$ and $16: 8$ (L:D) photoperiod during larval to adult stage. For culture maintenance, second instar larvae were transferred to cabbage leaves kept in plastic jars $(25 \times 20 \mathrm{~cm})$ covered with a muslin cloth $(4 \mathrm{~mm})$. The larvae were regularly provided with fresh leaves without removing the infested one so as to enable them to shift to fresh leaves on their own, to improve their survival rate and reduce the handling time considerably. The pupae were collected and placed in clean cages for adult emergence. For mating and oviposition, adult moths were collected with an aspirator and transferred to oviposition cages $(27 \times 21 \times 21 \mathrm{~cm})$. For oviposition, the bottom of the boxes were covered with tissue paper and on which cabbage leaves were provided by placing their petiole in Erlenmeyer flask filled with tap water. Adult moths were provided with $5 \%$ honey solution as food in cotton wool in Petri dishes ( $35 \mathrm{~mm}$ ).

Oviposition experiments: Oviposition experiments were designed to evaluate the oviposition deterrence activity of adult females of $P$. xylostella to methanol and hexane extract of $A$. calamus and $V$. negundo (treatments) comparison to the crucifer host (control). Two cabbage potted plants were placed into each cage on opposite sides of oviposition cages $(27 \times 21 \times 21 \mathrm{~cm})$. Leaves of one potted plant was treated with plant extracts and other plant was treated with only solvent. For preparing formulation of plant extract, Triton X-100 (0.1\% (w/v) and solvent $(10 \%)$ was added. The control formulation was prepared without 
adding the plant extract.The treatments were applied using a small hand-held sprayer (Shivam Agrotech, Rajkot, Gujarat, India). The plants were sprayed until run-off (approximately 100 $\mathrm{ml}$ per plant) and then left to dry for one hour before being placed in a cage. The cages were arranged randomly on the laboratory bench. Five male and female moths were collected after 10-12 hrs of emergence, adult moths were sexed on the basis of their wing colour, male moth possess dark brown wings, however female moth possess tan coloured wings and released into oviposition cages. Placement of adult moths in the cages was done at around 6 p.m. Once placed in the cages, moths were allowed to freely mate and oviposit on the offered host plants. Cotton wools saturated with $5 \%$ honey solution were placed in cages to serve as feeding sites. After exposing the plants to adult female for $24 \mathrm{hr}$ number of eggs laid on treated and un-treated plant was counted. Eggs laid at other sites in the cage were ignored. The experiment was three replicates for each concentration.

Ovipositional response to concentrations: Different concentrations $(0.625,1.25,2.5$ and $5.0 \%)$ of crude extract was formulated by serial dilution method. The oviposition deterrence activity of different plant extracts at different concentrations was measured by this experiment. For each concentration, there were three replicates.

Residual activity: The residual activity of different plant extracts applied to treated surface of potted plant to female of $P$. xylostella were evaluated from 0 to 3 days. There were three replicates per treatment.

Antifeedant activity: The third instar larvae of $P$. xylostella were used for measuring the antifeedant activity of different plant extracts. The leaf discs of cabbage $\left(30 \mathrm{~cm}^{2}\right)$ were dipped in four concentrations ranging from 0.625 to $5.0 \%$ and then placed over bed of agar gel in Petri-plates. One set was also maintained without any treatment in Petri-plate to serve as control. Third instar larvae $(n=10)$ of diamondback moth, pre-starved for 6 hrs were released in the centre of the leaf disc in Petri plates and were kept in the growth chamber for $24 \mathrm{hrs}$ and experiment was replicated five times. In each treatment, leaf area was determined using digital leaf area analyzer (Winfolia; Regent Inc, Canada) prior to initiating the experimentation and after $24 \mathrm{hrs}$ of contact.

Statistical analyses: The data on number of eggs laid by adult female on treated potted plant and un-treated plant were analyzed by t-test for paired comparisons by using statistical package for the social sciences (SPSS) software version 16. The significance of differences was checked at the level of $5 \%$. Before performing analysis the data were log-transformed.

$$
\text { Oviposition deterrent indices }=\frac{100(C-T)}{C+T}
$$

Where, $T$ and $C$ are the mean number of eggs laid on treated potted plant and un-treated plant. For the calculation of index, data were not log-transformed. Oviposition deterrent indices (ODI) were calculated as per Huang et al. (1995).

The per cent antifeedance for each treatment was calculated as per Govindachari et al. (1994).

\section{Results and Discussion}

Cabbage leaves treated with plant extract of $A$. calamus (methanol) and $V$. negundo (hexane), significantly deterred the oviposition of diamondback moth under dual choice test $(t=4.09$, $\mathrm{df}=4, P=0.016$, and $t=4.98, \mathrm{df}=4, P=0.008$, respectively). At a concentration of $0.625 \%(\mathrm{w} / \mathrm{v})$ methanol extract of $A$. calamus showed highest deterrent effect $(\mathrm{ODI}=11.7)$ as compared to hexane extract of $V$. negundo (ODI=6.6). However non-significant deterrent effect on female moths was observed when leaves treated $0.625 \%(\mathrm{w} / \mathrm{v})$ concentration of $A$. calamus (hexane) and $V$. negundo (methanol) extract $(t=3.69$, $d f=4, P=0.302$ and $t=1.33$, $\mathrm{df}=4, P=0.253$, respectively). Lowest $\mathrm{ODI}$ values of the test materials indicated less deterrent effect (Table 1). Host-plant finding by adult insects in crucifers may depend on the emanation of plant volatiles and plant acceptance may depend on glucosinolates that are perceived upon contact with the plant (Renwick, 2002; Reed et al., 1989). Previous study showed that ethanolic fruit extracts of syringe plant have been shown oviposition deterrence to P. xylostella (Chen et al., 1996). In the present, cabbage potted plants treated with methanol and hexane extract of $A$. calamus and $V$. negundo inhibits the egg

Table 1 : Oviposition by Diamondback moth, Plutella xylostella on cabbage leaves treated with Acorus calamus and Vitex negundo plant extracts at a concentration of $0.625 \%(\mathrm{w} / \mathrm{v})$

\begin{tabular}{|c|c|c|c|c|c|c|}
\hline \multirow[t]{2}{*}{ Plants } & \multirow[t]{2}{*}{ Plant parts } & \multirow[t]{2}{*}{ Solvent } & \multicolumn{3}{|c|}{ Mean number of eggs laid ( $\pm S E)^{a}$} & \multirow[t]{2}{*}{$\mathrm{ODI}^{\mathrm{C}}$} \\
\hline & & & Treated & Control & $P$ value ${ }^{\mathrm{b}}$ & \\
\hline Acorus calamus & Rhizomes & $\mathrm{M}$ & $238 \pm 16$ & $301 \pm 30$ & 0.016 & 11.7 \\
\hline Acorus calamus & Rhizomes & $\mathrm{H}$ & $225 \pm 25$ & $246 \pm 21$ & 0.302 & 4.5 \\
\hline Vitex negundo & Leaves & $M$ & $174 \pm 15$ & $190 \pm 15$ & 0.253 & 4.4 \\
\hline Vitex negundo & Leaves & $\mathrm{H}$ & $219 \pm 18$ & $250 \pm 19$ & 0.008 & 6.6 \\
\hline
\end{tabular}

M: Methanol; $\mathrm{H}$ : Hexane; a average of five replication, $\mathrm{SE}=$ standard error; ${ }^{\mathrm{b}}$ statistical test refers to t-test for pair comparison between treated and control leaves; ${ }^{\circ} \mathrm{ODI}=$ oviposition deterrent index 
Table 2 : Oviposition by Diamondback moth, Plutella xylostella on cabbage leaves treated with Acorus calamus and Vitex negundo plant extracts according to concentration

\begin{tabular}{|c|c|c|c|c|}
\hline \multirow[t]{2}{*}{ Concentration (\%w/v) } & \multicolumn{3}{|c|}{ Mean number of eggs laid ( $\pm S E)^{a}$} & \multirow[t]{2}{*}{$\mathrm{ODI}^{\mathrm{c}}$} \\
\hline & Treated & Control & $P$ value & \\
\hline \multicolumn{5}{|l|}{ Acorus calamus (M) } \\
\hline 0.625 & $238 \pm 16$ & $301 \pm 30$ & 0.016 & 11.7 \\
\hline 1.25 & $194 \pm 12$ & $285 \pm 14$ & 0.000 & 19.0 \\
\hline 2.5 & $103 \pm 22$ & $185 \pm 25$ & 0.002 & 28.5 \\
\hline 5.0 & $106 \pm 10$ & $240 \pm 21$ & 0.001 & 38.7 \\
\hline \multicolumn{5}{|l|}{ Acorus calamus (H) } \\
\hline 0.625 & $225 \pm 25$ & $246 \pm 21$ & 0.302 & 4.5 \\
\hline 1.25 & $168 \pm 15$ & $189 \pm 07$ & 0.091 & 5.9 \\
\hline 2.5 & $179 \pm 08$ & $228 \pm 22$ & 0.002 & 12.0 \\
\hline 5.0 & $150 \pm 25$ & $226 \pm 28$ & 0.021 & 20.2 \\
\hline \multicolumn{5}{|l|}{ Vitex negundo(M) } \\
\hline 0.625 & $174 \pm 15$ & $190 \pm 15$ & 0.253 & 4.4 \\
\hline 1.25 & $163 \pm 08$ & $200 \pm 27$ & 0.064 & 10.2 \\
\hline 2.5 & $110 \pm 18$ & $145 \pm 16$ & 0.040 & 13.7 \\
\hline 5.0 & $120 \pm 18$ & $175 \pm 14$ & 0.017 & 18.6 \\
\hline \multicolumn{5}{|l|}{ Vitex negundo $(\mathrm{H})$} \\
\hline 0.625 & $219 \pm 18$ & $250 \pm 19$ & 0.008 & 6.6 \\
\hline 1.25 & $168 \pm 23$ & $215 \pm 32$ & 0.026 & 12.3 \\
\hline 2.5 & $152 \pm 38$ & $231 \pm 20$ & 0.013 & 20.6 \\
\hline 5.0 & $95 \pm 30$ & $160 \pm 18$ & 0.037 & 25.5 \\
\hline
\end{tabular}

M: Methanol; $\mathrm{H}$ : Hexane; a average of five replication, $\mathrm{SE}=$ standard error; ${ }^{\mathrm{b}}$ statistical test refers to t-test for pair comparison between treated and control leaves; ${ }^{\circ} \mathrm{ODI}=$ oviposition deterrentindex

Table 3: Oviposition by Diamondback moth, Plutella xylostella on cabbage leaves treated with Acorus calamus and Vitex negundo plant extracts (1.25\% w/v) at different days after treatment

\begin{tabular}{|c|c|c|c|c|}
\hline \multirow[t]{2}{*}{ DAT $^{\mathrm{a}}$} & \multicolumn{3}{|c|}{ Mean number of eggs laid ( $\pm S E)^{a}$} & \multirow[t]{2}{*}{$\mathrm{ODI}^{\mathrm{c}}$} \\
\hline & Treated & Control & $P$ value & \\
\hline \multicolumn{5}{|c|}{ Acorus calamus (M) } \\
\hline 0 & $194 \pm 12$ & $285 \pm 14$ & 0.000 & 19.0 \\
\hline 1 & $248 \pm 18$ & $369 \pm 06$ & 0.000 & 19.6 \\
\hline 2 & $206 \pm 18$ & $265 \pm 32$ & 0.039 & 12.5 \\
\hline 3 & $99 \pm 15$ & $114 \pm 11$ & 0.088 & 7.0 \\
\hline \multicolumn{5}{|c|}{ Acorus calamus (H) } \\
\hline 0 & $168 \pm 15$ & $189 \pm 07$ & 0.091 & 5.9 \\
\hline 1 & $188 \pm 12$ & $207 \pm 13$ & 0.027 & 4.8 \\
\hline 2 & $136 \pm 16$ & $153 \pm 11$ & 0.055 & 5.9 \\
\hline 3 & $91 \pm 23$ & $98 \pm 13$ & 0.672 & 3.7 \\
\hline \multicolumn{5}{|c|}{ Vitex negundo (M) } \\
\hline 0 & $163 \pm 08$ & $200 \pm 27$ & 0.064 & 10.2 \\
\hline 1 & $145 \pm 10$ & $177 \pm 15$ & 0.029 & 9.9 \\
\hline 2 & $159 \pm 14$ & $138 \pm 19$ & 0.137 & -7.1 \\
\hline 3 & $108 \pm 22$ & $100 \pm 16$ & 0.306 & -3.8 \\
\hline \multicolumn{5}{|c|}{ Vitexnegundo $(\mathrm{H})$} \\
\hline 0 & $168 \pm 23$ & $215 \pm 32$ & 0.026 & 12.3 \\
\hline 1 & $326 \pm 14$ & $379 \pm 12$ & 0.005 & 7.5 \\
\hline 2 & $173 \pm 16$ & $197 \pm 14$ & 0.025 & 6.5 \\
\hline 3 & $83 \pm 06$ & $90 \pm 11$ & 0.219 & 4.0 \\
\hline
\end{tabular}

${ }^{a} \mathrm{DAT}=$ days afer treatment; M: Methanol; $\mathrm{H}$ : Hexane; average of five replication, $\mathrm{SE}=$ standard error; ${ }^{\mathrm{b}}$ statistical test refers to t-test for pair comparison between treated and control leaves; ${ }^{\circ} \mathrm{ODI}=0$ viposition deterrent index 

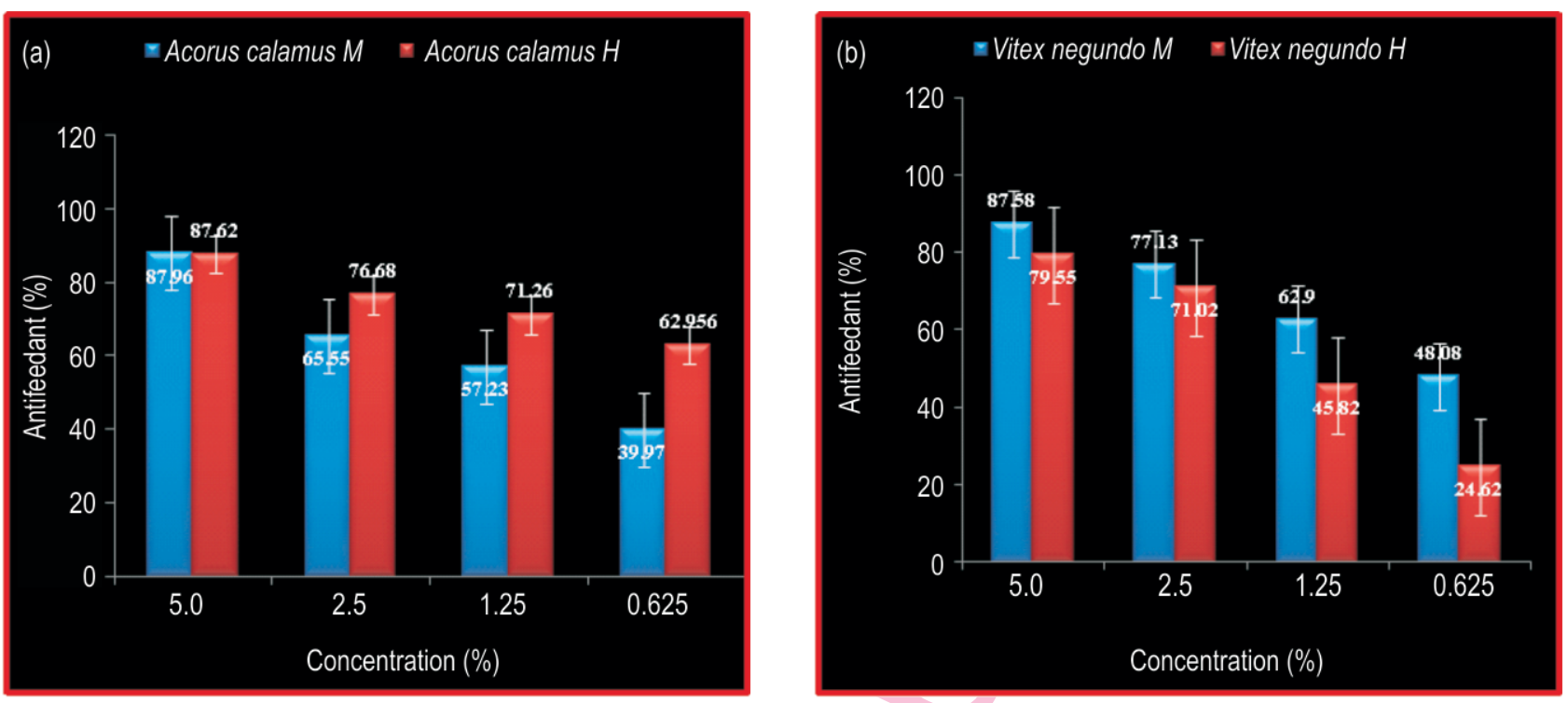

Fig. 1 : Effect on antifeedant activity against third instar larvae of Plutella xylostella (a)A Acorus calamus and (b) Vitex negundo.

laying of the females of $P$. xylostella (Table2). Earlier, ovisposition deterremt activity of $A$. calamus and $V$. negundo to females of $P$. xylostella due to present of active compound $\beta$-asarone (Murthy et al., 2005; Liu et al., 2013 and Raja et al., 2009). However, V. negundo leaves contained an alkaloid nishidine, flavonoids like flavones, luteolin-7-glucoside, casticin, iridoid glycoside, an essential oil and other constituents like vitamin- $C$, carotene, benzoic acid, $\delta$-guaiene and C-glycoside (Khokra et al., 2008). Feeding cabbage leaves treated with extract of $A$. indica at 0.5 per cent concentration to $P$. xylostella resulted in 50.33 per cent reduction in egg laying by this pest (Patil and Goud 2003), confirming the present study. Methanol and dichloromethane extract of $A$. calamus showed oviposition deterrent activity to Callosobruchus maculatus (Jayakumar et al., 2005). Oviposition deterrence activity of limonoid allelochemicals and Chrysanthemum morifolium to $P$. xylostella were also reported by Akhtar and Isman (2003) and Liu et al. (2006).

The results of the present study indicated that untreated and treated leaves with lowest concentration $(0.625$ and $1.25 \%$ w/v) of hexane extract of $A$. calamus showed a non-significant difference for egg laying by diamondback moth $(P=0.302$, $t=1.183, \mathrm{df}=4$ and $P=0.091, t=2.212, \mathrm{df}=4$, respectively) and $V$. negundo methanol extract $(P=0.253, t=1.334, \mathrm{df}=4$ and $P=0.064$, $t=2.546, \mathrm{df}=4)$. The ODI values at $0.625 \%$ concentration were 4.5 and 4.4 for $A$. calamus hexane and $V$. negundo methanol extract respectively. Female of diamondback moth laid significantly lower number of eggs at higher concentration on cabbage leaves treated with hexane and methanol extract of $A$. calamus and $V$. negundo, respectively.

As the concentration of $A$. calamus and $V$. negundo extract increased, an increase in ODI value was also observed
(Table 2). At the highest concentration none of the plant extract completely deterred the oviposition by diamondback moth. Methanol and hexane extract of $A$. calamus and $V$. negundo at a concentration of $5.0 \%(\mathrm{w} / \mathrm{v})$ showed 38.7 and $25.5 \mathrm{ODI}$, respectively. Results from the present study showed that $P$. xylostella larvae were able to detect the $A$. calamus and $V$. negundo extract. At high doses these botanical insecticides also had a significant impact on the behaviour of larvae. Our results collaborate with the findings of Rana et al. (2013) who also observed that increase in concentration of extract of Artemesia annua resulted in decrease in egg laying of Callosobruchus chinensis. Moreover, Prathibha et al. (2014) also observed that as the concentration of Eugenia jambolana increased from 20-100 $\%$ the mean ovipostion deterrent activity increased to Culex quinquefasciatus. The results of this study collaborate with the findings of Adesina and Ofuya (2015) who observed increase in concentration of methanol leaf extract of Secamone afzelii resulted in reduction in number of egg laying from 51.61 to 30.62 . The present results revealed that cabbage plant treated with methanol extract of $A$. calamus and hexane extract of $V$. negundo deterred the females of $P$. xylostella to lay eggs in a concentrationdependent manner.

The leaves treated with hexane extract of $V$. negundo showed a decline oviposition deterrent effect as ODI value decreased from 12.3 at 0 day to 4.0 at 3 day, however hexane and methanol extract of $A$. calamus and $V$. negundo showed relatively less change in ODI values. However, oviposition deterrence of $A$. calamus methanol extract increased after first day then decreased with time. A significant differences were evident in the number of eggs laid by diamondback moth on leaves treated with methanol extract of $A$. calamus and control leaves (first day, $t=18.92, d f=4, P=0.00$; second day, $t=3.424$, 
$\mathrm{df}=4, P=0.039)$, while on third day no significant differences were found $(P=0.088, \mathrm{df}=4, t=2.247$ ). Adult females laid significantly different number of eggs on leaves treated with $V$. negundo hexane extract and control leaves (first day, $t=5.455$, $d f=4$, $P=0.005$; second day, $t=4.92, \mathrm{df}=4, P=0.025$ ) (Table 3 ). A non significant difference in egg laying in both treatments and control were observed with $A$. calamus hexane and $V$. negundo methanol extract at 0, 2 and 3DAT, however on the first day there was significant difference in egg laying. Leaves treated with $A$. calamus and $V$. negundo showed different ODI values that tended to decline with increasing time (0 to 3 DAT). Highest residual activity of methanol extract of $A$. calamus was observed at 3 DAT, which maybe due to its low volatility, but varied residua activity given by hexane extract of $A$. calamus. In contrast, the effect of unstable compound of $V$. negundo decreased with increasing time (0 to 3 DAT) (Table 3). Patil et al. (2003) reported the mean egg laying by $P$. xylostella decreased from 56.7 to 32.66 on plant surface treated with $A$. calamus (aqueous extract) as the time increased from 0 to 3 days. Similarly, Basukriadi and Wilkins (2014) also reported the residual effect of yam been seed extract (1\%) as egg laying decreased from 1 to 3 days from 77 to 59 of $P$. xylostella. Plant extracts having nonvolatile properties are more useful compounds for oviposition deterrent (Renwick, 1988).

In the present study, the antifeedant activity varied significantly based on the solvents used for extraction. Antifeedant effects of different plant extracts were evaluated based on leaf area consumed by larvae of $P$. xylostella. Among the two plant extracts, methanol and hexane extract the $A$. calamus $(5 \%)$ concentration showed 87.96 and $87.68 \%$ antifeedant activity to $P$. xylostella, respectively. However, among the plant extract of $V$. negundo the maximum antifeedant activity was with methanol extract $(87.58 \%)$ as compared to hexane extract $(79.55 \%)$ at $5 \%$ concentration. Antifeedant activity of both plants extracts decreased with the decrease in concentration (Fig. 1). During the present investigation, it was observed that larvae highly preferred to feed on control cabbage leaf and less leaf area was consumed on the treated cabbage leaf. The present investigation is in agreement with Murthy et al. (2005) who reported that mustard leaves treated with aqueous extract $(2.5 \%)$ of $A$. calamus, V. negundo and Strychnos nux-vomica L., when fed to larvae reduced feeding of $P$. xylostella. Leaf disc of Brassica oleracia $L$. when treated with aqueous extract of Vitex trifolia L., $A$. calamus and Lantana camara $L$ gave protection against third instar larvae of $P$. xylostella (Hemchandra and Singh, 2006; Sharma et al., 2001). Similarly, antifeedant activities of essential oils of $A$. calamus were also reported against lepidopteran pest by Melani et al. (2016).

The results of the present study reveals that cabbage plants treated with methanol and hexane extracts of $A$. calamus and $V$. negundo showed oviposition deterrent and antifeedant activity to $P$. xylostella. So, both the plant extracts may be useful for the management of this pest under real field conditions.

\section{Acknowledgments}

Thanks are due to the Head, Department of Entomology, CSK, Himachal Pradesh Krishi Vishvavidyalaya for providing necessary laboratory facilities. Thanks also to Dr. Ajay Kumar Sood for providing guidance and information to develop the experiment.

\section{References}

Adesina, J.M. and T.I. Ofuya: Oviposition deterrent and egg hatchability suppression of Secamone afzelii (Schult) K. Schum leaf extract on Callosobhuchus maculatus (Fabricius) (Coleoptera: Chrysomelidae). Jordan J. Bio. Sci., 8, 95-100 (2015).

Ahmad, T. and M.S. Ansari: Studies on seasonal abundance of diamondback moth, Plutella xylostella (lepidoptera: Plutellidae) on cauliflower crop. J. Plant. Prot. Res., 50, 280-287 (2010).

Akhtar, Y. and M.B. Isman: Larval exposure to oviposition deterrent alters subsequent oviposition behavior in generalist, Trichoplusiani and specialist, Plutella xylostella moths. J. Chem. Ecol., 29, 1853-1870 (2003).

Basukriadi, A. and R.M. Wilkins: Oviposition deterrent activities of Pachyrhizus erosus seed extract and other natural products on Plutella xylostella (Lepidoptera: Plutellidae). J. Insect. Sci., 14, 1-6 (2014).

Chen, C.C., S.J. Chang, R.F. Hou and L.I. Cheng: Deterrent effect of the chinaberry extract on oviposition of the diamondback moth, Plutella xylostella (L.) (Lepidoptera: Plutellidae). J. Appl. Entomol., 120, 165-169(1996).

Dhaliwal, G.S. and O.P. Koul.: Biopesticides and Pest Management: Concepts and Approaches. $2^{\text {nd }}$ Edn., Kalyani Publishers, Inc., New Delhi (2011).

Elumalai, K., A. Jayasankar, M. Jaykumar, N. Raja and S. Ignacimuthu: Sustainable Insect Management. $1^{\text {st }}$ Edn., Narosa Publishing House, Inc., New Delhi (2005).

Govindachari, T.R., G. Suresh and K.G. Prasad: Structure related antifeedant activities of azadirachtins against the tobacco cutworm, Spodoptera litura F. Pest. Res. J., 6, 20-25 (1994).

Hemchandra, O. and T.K. Singh: Evaluation of antifeedant properties of some plant extract against diamondback moth, Plutella xylostella (Linn.). Pestology, 30, 36-39 (2006)

Huang, X.P., J.A.A. Renwick and F.S. Chew: Oviposition stimulants and deterrents control acceptance of Alliaria petiolata by Pieris rapae and Pieris napioleracea. Chemoecology, 5, 79-87 (1995).

Jacobson, M.: Glossary of Plant Derived Insect Deterrents. $1^{\text {st }}$ Edn., CRC Press, Inc., Florida (1989).

Jayakumar, M., W.S. John and S. Ignacimuthu: Evaluation of some plant extracts on the oviposition deterrent and adult emergency activity of Callosobruchus maculatus F. (Bruchidae: Coleoptera). Pestology, 29, 37-41(2005).

Khokra, S.L., O. Prakash, S. Jain, K.R. Aneja and Y. Dhingra: Essential oil composition and antibacterial studies of Vitex negundo Linn. extracts. Indian. J. Pharm. Sci., 70, 522-526 (2008).

Liu, S.S., Y.H. Li and Y.G. Lou: Non-host plant extracts reduce oviposition of Plutella xylostella (Lepidoptera: Plutellidae) and enhance 
parasitism by its parasitoid Cotesia plutellae (Hymenoptera Braconidae). Bull. Entomlo. Res., 96, 373-378 (2006).

Liu, X.C., L.G. Zhou, Z.L. Liu and S.S. Du: Identification of insecticidal constituents of the essential oil of Acorus calamus rhizomes against Liposcelis bostrychophila Badonnel. Molecules, 18, 5684 5696 (2013).

Martínez-Castillo, M., J.L. Leyva, J. Cibrián-Tovar and R. Bujanos Muñiz Parasitoid diversity and impact on populations of the diamondback moth, Plutella xylostella (L.) on Brassica crops in Central Mexico. Biocontrol, 47, 23-31 (2002).

Milani, D., T. Himawan and A. Afandhi: Bioactivity of sweet flag (Acorus calamus Linnaeus) essential oils against Spodoptera litura Fabricius (Lepidoptera: Noctuidae). The J. Tropi. Sci., 6, 86-90 (2016).

Murthy, M.S., P.S. Jagadeesh and M. Thippaiah: Repellant, antifeedant and ovicidal action of some plant extracts against the diamondback moth, Plutella xylostella (L.) (Lepidoptera: Yponomeutidae). Pest. Manag. Econ. Zool., 13, 1-7 (2005).

Patil, R.S. and K.B. Goud: Efficacy of methanolic plant extracts as ovipositional repellents against diamondback moth, Plutella xylostella (L.). J. Entom. Res. Socie., 27, 13-18 (2003).

Prathibha, K.P., B.S. Raghavendra and V.A. Vijayan: Larvicidal, ovicida and oviposition deterrent activities of four plant extracts against three mosquito species. Environ. Sci. Pollut Res., 21, 6736-6743 (2014).

Raja, A.E., M. Vijayalakshmi and G. Devalarao: Acorus calamus Linn.: Chemistry and Biology. Res. J. Pharm. Tech., 2, 256-261 (2009).

Ramya, S., C. Rajasekaran, T. Kalaivani, G. Sundararajan and R. Jayakumararaj: Biopesticidal effects of leaf extracts of Catharanthus roseus $\mathrm{L}$. on the larvae of gram pod borer
Helicoverpa armigera (Hubner). Ethnobot. Leaflets, 12, 1096-1101 (2008).

Rana, K., K.C. Sharma and H.S. Kanwar: Oviposition deterrent activity of some indigenous plant extracts against Pulse beetle, Callosobruchus chinensis L. infesting pea in storage. Inter. J. Bioresour. Stress Manag., 4, 362-364 (2013).

Reed, D.W., K.A. Pivnick and E.W. Underhill: Identification of chemical oviposition for the diamondback moth, Plutella xylostella, present in three species of Brassicaceae. Entomol. Exp. App., 53, 277-286 (1989).

Renwick, J.A.A.: The chemical world of crucivores: Lures, treats and traps. Entomol. Exp. App., 104, 35-42 (2002).

Renwick, J.A.A.: Plant constituents as oviposition deterrents to lepidopterous insects. In: Biologically Active Natural Products: Potential use in Agriculture (Ed.: H.G. Cutler). Washington: American Chemical Society, pp. 379-385 (1988).

Sarfraz, M., L.M. Dosdall and B.A. Keddie: Diamondback moth-host plant interaction: Implication for pest management. Crop. Protect., 25, 625-639 (2006).

Sharma, S.S., K. Gill, M.S. Malik and O.P. Malik: Insecticidal, antifeedant and growth inhibitory activities of essential oils of some medicinal plants. J. Med. Aro. Plant Sci., 22, 373-377 (2001).

Singh, R.P.: Botanicals in pest management: An ecological prospective. In: Pesticides and Environment (Eds.: G.S. Dhariwal and B. Singh). Common Wealth Publishers. Inc., New Delhi, p.56 (2000)

Talekar, N.S. and A.M. Shelton: Biology ecology and management of the diamondback moth. Ann. Rev. Entomol., 38, 275-301 (1993).

Tewary, D.K., A. Bhardwaj and A. Shanker: Pesticidal activities in five medicinal plants collected from mid hills of Western Himalayas. Ind. Crops. Prod., 22, 241-247 (2005). 